Revista Mídia e Cotidiano

Artigo Seção Temática

Volume 11, Número 1, abril de 2017

Submetido em: 10/04/2017

Aprovado em: 30/04/2017

\title{
AS REPRESENTACÕES SOCIAIS DA IDENTIDADE SURDA E O DIREITO AO RECONHECIMENTO
}

\section{THE SOCIAL REPRESENTATIONS OF DEAF IDENTITY AND THE RIGHT TO RECOGNITION}

\author{
Márcia VIDAL NUNES ${ }^{1}$; Marina GOMES PORTELA ${ }^{2}$
}

Resumo: Este artigo pretende contribuir com a luta pelo reconhecimento e direitos dos surdos, através de diferentes campos do saber, como a Educação, no intuito de identificar as variadas concepções sobre cultura surda e as representações sociais, buscando distintas maneiras de se fazer entender. Há momentos em que é destacada as mudanças ao longo da história, decorrentes de diferentes posturas ideológicas nos modos de pensar a comunicação bilíngue, a importância da alteridade e a inclusão social além dos direitos adquiridos. Outro ponto que será abordado, nesta pesquisa, são os Estudos Surdos, que, em Comunicação, procuram problematizar as questões antes não discutidas. Um desses temas centrais envolvem as representações hegemônicas e ouvintistas sobre as identidades surdas. Seguindo essa linha de pesquisa, devemos refletir, a fim de desvelar os limites para que sejam incorporadas novas possibilidades de comunicação, com o desígnio de melhorar as condições de relacionamento da sociedade como um todo.

Palavras-chave: Comunicação; Cultura surda; Inclusão social; Representações sociais.

Abstract: This article aims to contribute to the struggle for the recognition and rights of the deaf, through different fields of knowledge, such as Education, in order to identify the different conceptions about deaf culture and social representations, searching for different ways of making themselves understood. There are moments in which the changes throughout history are highlighted, arising from different ideological positions in bilingual communication modes of thought, the importance of alterity and social inclusion beyond acquired rights. Another point, that will be approached in this research, is the Deaf Studies, which, in Communication, try to problematize the issues previously not discussed. One of these central themes involves the hegemonic and listener representations on deaf identities. Following this line of research, we must reflect, in order to unveil the limits to incorporate new possibilities of communication, with the aim of improving the conditions of society as a whole.

Keywords: Communication; Deaf culture; Social inclusion; Social representations.

1 Jornalista, doutora em Sociologia e professora do Programa de Pós-Graduação em Comunicação da Universidade Federal do Ceará (UFC). E-mail: marciavn@hotmail.com.

2 Jornalista e mestre pelo Programa de Pós-Graduação em Comunicação da Universidade Federal do Ceará (UFC). E-mail: marinagportela@hotmail.com. 


\section{míiA

Introdução

As expressões "cultura e identidade surdas" têm alcançado sua legitimidade, sobretudo, através da defesa da língua de sinais como a língua natural dos surdos. Essa alegação acontece por meio de uma inversão teórica, que trata a língua como responsável pelas práticas e interações sociais. Defender a língua de sinais está além de significar uma auto-suficiência e o direito de pertença a um mundo particular. Corrobora também a proteção das características da humanidade para ser considerado homem, como a linguagem.

A separação de grupos de pessoas acontece socialmente, assim como sua integração, posto que toda forma de discriminação do comportamento humano está subordinada à cultura que os constrói e sedimenta (SACKS, 1998). As regras sociais são responsáveis por essa separação, normas que organizam a vida social, modos de falar e de atuar no mundo. A forma como a surdez vem sendo tratada está ideologicamente relacionada a essas regras, bem como a luta política por novas normas: cultura e identidade surdas e inclusão social dos surdos passando a serem vistos como um grupo minoritário.

O esforço pela inclusão é uma forma de sair da "anormalidade" e aproximar-se das minorias, consideradas normais, embora diferentes. Essa mudança de estatuto da surdez, passando de patologia para fenômeno social, é acompanhada por uma mudança de nomenclatura, não somente terminológica, mas conceitual: de deficiente auditivo para surdo, ou ainda Surdo. Antes, a surdez era considerada uma doença. Agora, eles já são vistos como "diferentes".

Os termos deficiente auditivo - considera a surdez patológica -, surdo - usado com "s" minúsculo, para se referir à sua condição audiológica de não ouvir - e Surdo, com "S"33 maiúsculo, para representá-lo como sujeito cultural e político (WILCOX; WILCOX, 2005), são termos marcados ideologicamente. Conceder à língua de sinais o estatuto de língua vai além da linguística e de questões cognitivas, pois acarreta repercussões sociais.

\footnotetext{
3 Essa diferenciação entre "s/S" foi feita, pela primeira vez, em 1972, pelo sociolinguista James Woodward. Agora, ela é compreendida e utilizada pela maioria dos escritores do campo. Fonte: WRIGLEY (2006).
} 
Desde o momento em que se configura a língua de sinais como língua do surdo, o regimento do que é tido como normal muda. Assim, a língua de sinais possibilita a legitimação do Surdo como sujeito, transformando a anormalidade em diferença.

Esse pensamento se encaixa com o conceito de alteridade, o qual não vê o surdo de forma subalterna, aceitando-o como um sujeito político, que se forma a partir das representações sobre a sua diferença, onde a identidade surda é reconhecida, a fim de descartar o pensamento de inferioridade (WILCOX; WILCOX, 2005). O sujeito é construído desde o momento em que se aproxima de um meio e vivencia situações diversas de representação. Vale salientar que os discursos que constituem as representações são responsáveis pelo empoderamento desigual, fazendo com que alguns membros do grupo ocupem espaços de liderança dentro daquele círculo. Foucault (1990) faz uma reflexão a respeito das relações de poder que ocupam lugares diferenciados. Por exemplo, um pesquisador pode enxergar a situação dos surdos a partir de uma perspectiva que ele se permite pensar.

Aqui, nota-se o uso das palavras "surdo", "surda" e "Surdo" utilizando os conceitos de "s/S". Os Surdos têm uma identidade surda, que se apresenta de diferentes formas, porque está vinculada ao meio em que vivem e frequentam e não somente à linguagem pois esta não é um referente fixo, já que é construída no cotidiano. Suas características mudam de acordo com o tempo, com os grupos culturais, seu espaço geográfico, o momento histórico e os sujeitos, como afirma Wrigley (2006):

\begin{abstract}
A modalidade de linguagem que é (manifestada através) a linguagem de sinais torna visível uma variação de suposições (e ironias concomitantes) das tradições culturais há muito normalizadas. A constante exigência da regeneração contemporânea da cultura dos Surdos, sem limitações e assistência dos laços das gerações cruzadas, é uma diferença entre a cultura dos Surdos e a dos com audição. Tanto os aspectos espaciais e temporais de uma estrutura cognitiva que seja "inerentemente" Surda estão também personificados na modalidade linguística pela qual a cultura é carregada. As linguagens de sinais constroem a espacialidade numa gramática e sintaxe baseadas no visual que não estão disponíveis às linguagens baseadas no som. Certos aspectos dessas culturas não podem ser adequadamente transmitidos através deste (um inglês escrito) veículo textual, um veículo ligado à modalidade e à ontologia do som (WRIGLEY, 2006, pp. 10-11).
\end{abstract}

Este artigo, sobre as representações sociais da identidade surda e o direito ao reconhecimento, parte da premissa de que a comunidade Surda pode ser vista de uma 
forma plural, na qual novas identidades surgem no grupo, com sua própria história. A formação de uma identidade depende, entre outras coisas, de como o sujeito é tratado e se manifesta no meio em que vive. A título de exemplo, um surdo que convive com ouvintes que consideram a surdez uma deficiência pode ter uma identidade firmada a partir dessa ótica. No entanto, um surdo que vive dentro de sua comunidade possui outras narrativas sobre a sua diferença e composição da sua identidade. O sociólogo Zygmunt Bauman (2003) fala com propriedade sobre a questão da comunidade e identidade. Para ele:

A procura da identidade não pode deixar de dividir e separar. E no entanto a vulnerabilidade das identidades individuais e a precariedade da solitária construção da identidade levam os construtores da identidade a procurar cabides em que possam, em conjunto, pendurar seus medos e ansiedades individualmente experimentados e, depois disso, realizar os ritos de exorcismo em companhia de outros indivíduos também assustados e ansiosos (BAUMAN, 2003, p. 21).

Bauman (2003) afirma que as fronteiras que dividem os grupos não diminuíram, ao contrário, parecem crescer a cada dia. A comunidade pode ser vista ao passo em que, seja ela imaginária ou real, represente a expressividade na realidade das pessoas e isso vai refletir no comunitarismo. O entendimento sobre o que é comunitário não necessita de uma construção, pois ele já está "completo e pronto para ser usado. Precede todos os acordos e desacordos. É um sentimento 'recíproco e vinculante'. É graças a esse entendimento que na comunidade as pessoas permanecem essencialmente unidas a despeito de todos os fatores que as separam" (BAUMAN, 2003, p. 15 e 16).

O esclarecimento sobre organicidade e coletividade mantém os integrantes unidos, transformando a comunidade em um ambiente onde podem ser encontrados a lealdade e o conforto, ou seja, acolhimento, assim como é inquestionável o seu sistema de valores. Como o entendimento é natural, "ela não pode sobreviver ao momento em que o entendimento se torna autoconsciente" (BAUMAN, 2003, p. 17). Logo, a comunidade que fala de si seria uma contradição, pois "numa verdadeira comunidade não há motivação para a reflexão, a crítica ou a experimentação (...) porque a comunidade é fiel à sua natureza" (BAUMAN, 2003, p. 17). 
Essa percepção de contradições de identidade e diferenças entre comunidades pode ser visualizada na de surdos e ouvintes. O entendimento de um sobre o outro e a reflexão que cada um faz de si. Para Raquel Paiva (2003), os muros e a autocrítica estabelecidos por Bauman (2003) trata do declínio da comunidade pelo sentimento de individualismo e autonomia. Antes, a comunidade tradicional prezava a ideia de que o indivíduo deve estar inserido em um grupo. Agora, a sociedade é constituída de massas nutridas pela informação que neutraliza os pensamentos. Esse enfraquecimento é ocasionado pelo consumismo, precarizando os laços que unem os grupos.

Este quadro geral propicia o fortalecimento do individualismo, com um apelo ao isolamento e à solidão como modo de vida. Solidão autoimposta no vértice da pirâmide social - com uma postura francamente segregacionista, cada vez mais independente do território, cuja vinculação dá-se apenas a partir dos serviços existentes - e solidão pela exclusão, da grande maioria populacional, cada vez mais deixada à margem das condições básicas de sobrevivência, que passam a não ser de responsabilidade do Estado (PAIVA, 2003, p. 34).

Nessa direção, é fundamental o papel da comunicação comunitária. Vale destacar as narrativas no interior de uma comunidade, porque seu entendimento pode definir a organicidade do corpo social, a maneira como uma comunidade se relaciona com o mundo e essa interpretação das falas determina o espírito da comunidade. "O sentido dos signos presentes no discurso é partilhado pela comunidade, que estrutura a linguagem, constituindo assim a comunidade linguística" (PAIVA, 2003, p. 57).

A comunicação na comunidade inclui o diálogo entre diferentes pessoas e gerações, interpretando o não-dito e o não-vivido (PAIVA, 2003). Os Surdos não duvidam da existência de suas identidades culturalmente distintas. As pessoas com audição é que apresentam dificuldade em admitir os processos culturais específicos, tratando os surdos como seres incapazes. O item a seguir trata da existência da cultura surda, desconhecida por muitos e ignorada, sendo considerada por estes uma cultura patológica, como já foi dito, uma subcultura ou até não cultura. Essas representações, em geral, são baseadas nas perspectivas comuns, nas quais os surdos são narrados de forma negativa. 


\section{A cultura surda e as representações sociais da identidade}

As culturas minoritárias convivem com os códigos da cultura que se estabelece dominante e normalizadora. Nesse discurso, Nídia de Sá4 (2006) afirma que a palavra "normalizar", que busca ter o sentido de "igualar", na verdade, enxerga o surdo como alguém que não pode ser considerado "normal", enquanto não tiver a capacidade de ouvir sons. Essa normalidade é atribuída a uma determinada identidade, avaliando as outras identidades de forma negativa (SÁ, 2006).

Podemos perceber que os elementos culturais são formados pela mediação simbólica, que possibilita a vida em comum. A cultura se expressa, por exemplo, por meio da linguagem, dos juízos de valores, da arte, organizando um grupo, com seus próprios códigos e formas de agir em cada ocasião (STROBEL, 2008). A medida que pessoas de um grupo vão inserindo-se em uma outra cultura, ela vai se recriar. Os Surdos são um grupo minoritário, que busca o reconhecimento por parte de grupos maiores, no cenário social. A palavra "cultura", nesse contexto, é interpretada como um campo subjetivo, que traz sentido à comunidade. Segundo Karin Strobel (2008):

Cultura surda é o jeito de o sujeito surdo entender o mundo e de modificá-lo a fim de torná-lo acessível e habitável ajustando-os com as suas percepções visuais, que contribuem para a definição das identidades surdas e das 'almas' das comunidades surdas. Isto significa que abrange a língua, as ideias, as crenças, os costumes e os hábitos de povo surdo. (STROBEL, 2008, p. 22).

Os episódios históricos inscritos e mais conhecidos no Brasil são circunstanciais aos fatos. Esses registros são encontrados com facilidade nos livros didáticos, no entanto, há diferentes versões importantes que são omitidas. Um exemplo disso é saber o que pensavam os índios e os escravos negros, quando os portugueses chegaram ao Brasil. Da mesma forma acontece com o povo surdo. São poucos os documentos divulgados que trazem a "voz" desses grupos. É difícil entender esse silêncio a respeito deles.

Para que haja registro histórico cultural é preciso estudar suas crenças culturais e linguísticas, a fim que sejam compreendidos. Através do conhecimento histórico cultural

4 Nídia Regina Limeira de Sá é mãe de surda, psicóloga, mestre e doutora em Educação. Ela trabalha como professora da Faculdade de Educação da Universidade Federal da Bahia (UFBA) e coordena o Espaço Universitário de Estudos Surdos (EU-SURDO) (SÁ, 2006). 
da comunidade Surda, podemos ter uma nova interpretação de fonte e literária, concedendo espaço à sua cultura, valores, hábitos, leis e linguagem, deixando aquela valorização em excesso sobre a história registrada pela visão do "colonizador".

\begin{abstract}
As identidades são, pelo seu lado, um outro campo de pesquisa para a História Cultural. Enquanto representação social, a identidade é uma construção simbólica de sentido, que organiza um sistema compreensivo a partir da ideia de pertencimento. A identidade é uma construção imaginária que produz a coesão social, permitindo a identificação da parte com o todo, do indivíduo frente a uma coletividade, e se estabelece à diferença. A identidade é relacional, pois ela se constitui a partir da identificação de uma alteridade. Frente ao eu ou ao nós do pertencimento se coloca a estrangeiridade do outro" (PESAVENTO, 2005, p. 54).
\end{abstract}

Podemos perceber como a identidade nos meios culturais é afetada por um poder de controle em tempos e espaços determinados. Stuart Hall (1997) reconhece três concepções distintas sobre a identidade, com as reflexões que estamos conceituando sobre a cultura surda. Para Hall (2005), um ponto crucial é desfazer as vertentes opostas, sedimentadas nas epistemologias tradicionais, através de um projeto político de oposição, pois suas movimentações "sempre foram acompanhadas de transtorno, discussão, ansiedades instáveis e um silêncio inquietante" (HALL, 2005, p. 263). Os conceitos de Hall (1997) são: o sujeito do iluminismo, o sociológico e o pós-moderno.

O sujeito do iluminismo é baseado no pensamento da pessoa humana como um ser centrado, dotado da capacidade de razão e de poderes, de consciência e de ação, que emergia no nascimento e com ela se desenvolvia, porém, mantendo sua essência ao longo de sua existência. Não havia espaço à construção de novas identidades, pois existia um padrão de representação cultural. O sujeito sociológico tem a consciência de que ele não é autossuficiente, mas formado a partir das relações com outras pessoas consideradas importantes para si, que passa seus valores, sentidos e símbolos, ou seja, sua cultura. É perceptível, nessa forma de pensar do sujeito sociológico, descrita por Hall (1997), a existência de uma visão mais aberta sobre a importância do meio social à formação do indivíduo. Essa concepção não ignora a ideia de essência do ser, mesmo que acredite na influência do social na construção do sujeito. O "eu" pode ser modificado pelo mundo exterior. 
O sujeito ainda tem um núcleo ou essência interior que é o "eu real", mas este é formado e modificado num diálogo contínuo com os mundos culturais "exteriores" e as identidades que esses mundos oferecem. (...) $\mathrm{O}$ fato de que projetamos a "nós próprios" nessas identidades culturais, ao mesmo tempo que internalizamos seus significados e valores, tornando-os "parte de nós", contribui para alinhar nossos sentimentos subjetivos com os lugares objetivos que ocupamos no mundo social e cultural. A identidade, então, costura (...) o sujeito à estrutura. Estabiliza tanto os sujeitos quanto os mundos culturais que eles habitam, tornando ambos reciprocamente mais unificados e predizíveis (HALL, 1997, p. 11 e 12).

Nesta, muitas justificativas são estabelecidas quando a sociedade se depara com as diferenças crescentes. Por exemplo, a exclusão dos surdos do mercado de trabalho, poderia ser explicada da seguinte forma: o surdo não foi suficientemente estimulado pelo meio em que vive para conseguir disputar no mercado de trabalho. Podemos visualizar esse tipo de pensamento também presente nos filmes, sobre a estrutura de cada um, o que levou uns produtores a pensarem na comunicação visual e outros não. Acontece que, segundo Hall (1997), o sujeito, antes estável e unificado, está se fragmentando, pois agora ele é formado por várias identidades e não apenas uma, podendo ser algumas delas contraditórias ou mal resolvidas. Logo, as identidades que criavam as paisagens sociais e que proporcionavam uma conformação subjetiva sobre uma carência real da cultura, entraram em declínio, devido às mudanças estruturais e institucionais. Esse processo gera o sujeito pós-moderno, sem uma identidade permanente. Para Hall (1997), a identidade:

[...] torna-se uma "celebração móvel": formada e transformada continuamente em relação às formas pelas quais somos representados ou interpelados nos sistemas culturais que nos rodeiam (Hall, 1987). É definida historicamente, e não biologicamente. O sujeito assume identidades diferentes em diferentes momentos, identidades que não são unificadas ao redor de um "eu" coerente. (...) Se sentimos que temos uma identidade unificada desde o nascimento até a morte é apenas porque construímos uma cômoda estória sobre nós mesmos ou uma confortadora "narrativa do eu" (HALL, 1997, p. 13).

De acordo com o autor, cada vez que os sistemas de significação e representação cultural aumentam, as pessoas tornam-se mais suscetíveis a adquirirem novas identidades, mesmo que estas sejam temporárias. A partir do pensamento de Hall (1997), podemos pesquisar mais a fundo as identidades do sujeito Surdo. É possível adquirir uma visão momentânea ou sobre uma conjuntura do Surdo. Um exemplo seria o pesquisador etnógrafo, que está suscetível a aderir a algumas características ou formas de pensar da 
comunidade Surda. Para ter uma visão do Surdo como portador de identidades culturais, é necessário enxergá-lo dentro da diferença, porque é nela, na flexibilidade das representações, que estão as alternativas de construção e desconstrução das identidades Surdas.

O conceito de descentralização faz menção ao fato de que o iluminismo projetou um modelo de ser humano considerado perfeito, que deveria ser desejado por todos. A tradição iluminista permanece nos tempos atuais e as características do pós-estruturalismo entram em confronto com esses velhos costumes, em busca de descentralizar as identidades, assumindo múltiplas culturas na sua formação. A etnografia, nesse caso, aparece como facilitadora, no momento de investigar essas identidades e suas relações de poder.

Sá (2006) alerta que existem surdos que mostram ser coniventes com o discurso hegemônico, porém não é de interessante à minoria Surda. Nesse embate, a cultura dos Surdos se recria, porém é desconhecida e ignorada. Como a surdez está localizada no corpo individual, a medicina perpetua a interpretação da surdez como uma incapacidade ou deficiência. Sá (2006) propõe a extensão do questionamento sobre surdez, pois entende que esse é o momento de contribuir, para que ocorra uma mudança sobre "as significações e práticas que a modernidade gerou" (SÁ, 2006, p. 47).

\section{A alteridade no processo de cidadania e o conceito de minoria}

Os sistemas de representação dos surdos nos permitem passar da cultura à questão da alteridade, da diferença e singularidade. A partir de Bhabha (1992), podemos observar como a alteridade proporciona estratégias que permitem amenizar a resistência cultural sobre o sujeito surdo. Nesse quesito, fazem parte: a história, a língua de sinais, a necessidade de haver uma comunicação visual e a educação apropriada. Juntas, essas particularidades constituem a cultura surda, como símbolos da produção de sentido do sujeito. Bhabha (1992) reconhece a alteridade através da cultura:

A alteridade cultural funciona como o momento da presença na teoria do différence. $\mathrm{O}$ destino da não satisfação se encontra preenchido pelo reconhecimento da alteridade como um símbolo (e não signo) da presença da significância do différence. A alteridade representa o ponto de equivalência ou identidade num currículo no qual o que necessita provar os limites é assumido. 
Nega-se qualquer conhecimento da alteridade cultural enquanto um signo diferencial, implicando condições especificamente históricas e discursivas solicitando uma construção de práticas e leituras diferentes (BHABHA, 1992, p. 180).

As noções de alteridade, diferença e identidade surgem como uma tática para designar a posição de representação do outro. A alteridade é responsável por formar parte da diferença cultural (PERLIN, 2003). Uma junção com essas especificidades representa a produção da identidade surda, traz sentido à pessoa surda, composta de costumes e características diversas, plenas de significados. Sobre o sentido de maioria e minoria, Sodré (2005) trata o conceito como importante denominação à democracia representativa.

\footnotetext{
Na democracia, diz-se, predomina a vontade da maioria. É verdade, mas é um argumento quantitativo. Qualitativamente, democracia é um regime de minorias, porque só no processo democrático a minoria pode se fazer ouvir. Minoria é, aqui, uma voz qualitativa. (...) Ora, a noção contemporânea de minoria - isto que aqui se constitui em questão - refere-se à possibilidade de terem voz ativa ou intervirem nas instâncias decisórias do Poder aqueles setores sociais ou frações de classe comprometidas com as diversas modalidades de luta assumidas pela questão social. Por isso, são considerados minorias os negros, os homossexuais, as mulheres, os povos indígenas, os ambientalistas, os antineoliberalistas, etc. $\mathrm{O}$ que move uma minoria é o impulso de transformação. É isso que Deleuze e Guattari inscrevem no conceito de "devir minoritário", isto é, minoria não como um sujeito coletivo absolutamente idêntico a si mesmo e numericamente definido, mas como um fluxo de mudança que atravessa um grupo, na direção de uma subjetividade não capitalista. Este é na verdade um "lugar" de transformação e passagem (SODRÉ, 2005, p. 11 e 12).
}

Em um primeiro momento, Sodré (2005) nos revela que o conceito de maioria está diretamente ligado ao ouvir. Quem alcança o patamar de se fazer ouvir deixa de ser minoria, o que é importante à democracia. Nesse caso, os surdos se encaixam no grupo das minorias, por não se expressarem por meio da voz, no sentido literal da palavra. Depois, o autor trata da questão de essas minorias terem alcançado voz, como um poder de interferência no sistema, em defesa de um ideal, através dos movimentos sociais.

No mundo contemporâneo, a cultura é vista como o meio de fazer política na sociedade. O conceito de minoria é o de "um lugar onde se animam os fluxos de transformação de uma identidade ou de uma relação de poder. Implica uma tomada de posição grupal no interior de uma dinâmica conflitual" (SODRÉ, 2005, p. 12). Devido a isso, pode-se dizer que o surdo, no Brasil, é mais propriamente um lugar - ou seja, o 
espaço ocupado, não necessariamente físico, mas um ponto que polariza as diferenças e orienta as identificações - em vez de uma pessoa definida somente pela falta de audição. Logo, minoria não significa uma junção que impulsiona, como uma multidão, mas é, antes de tudo, um dispositivo simbólico, com um propósito ético-político dentro da luta contrahegemônica (SODRÉ, 2005).

Muniz Sodré pontua quatro características gerais à definição de minoria. A primeira é a vulnerabilidade jurídico-social, ou seja, o grupo que se coloca como minoritário pode ser considerado vulnerável, perante a legitimidade institucional, e de políticas públicas, por não ser institucionalizado pelas regras do ordenamento jurídico-social vigente. Assim, a luta é para obter voz, no sentido de reconhecimento de seu discurso diante da sociedade.

O segundo ponto é a identidade in statu nascendi, isso quer dizer que, da perspectiva de identificação social, a minoria mostra-se "na condição de uma entidade em formação que se alimenta da força e do ânimo dos estados nascentes. Mesmo quando já existe há muito tempo, a minoria vive desse eterno recomeço" (SODRÉ, 2005, p. 13). Um exemplo é um grupo de surdos, mesmo que seja numeroso e já com certo tempo de existência, designa-se minoria ativa local.

A terceira característica é a luta contra-hegemônica, na qual uma minoria luta pela redução do poder predominante, entretanto, a princípio, não pretende tomar o poder através da força física ou armamento. Vale salientar que, nas tecnodemocracias ocidentais, a mídia é um dos principais meios utilizados para essa luta. Existe aí, a chance de as ações minoritárias serem realizadas, devido a sua repercussão midiática. Por último, Sodré caracteriza as estratégias discursivas e de ações demonstrativas, que são atos realizados na luta de seu reconhecimento e busca de direitos, através das "passeatas, invasões episódicas, gestos simbólicos, manifestos, revistas, jornais, programas de televisão, campanhas pela internet" (SODRÉ, 2005, p. 13).

Quanto mais a diferença for compreendida, combatendo as desigualdades sociais e as restrições de liberdade, mais próximos estaremos de um projeto político que vise à ampliação da intervenção cultural, em que as diversas culturas possam se exprimir e se entrelaçarem, gerando o conhecimento sobre o outro e incentivando a experiência da alteridade. Esse processo, de identificação do pensamento surdo, se faz possível através 
da alteridade. O encontro com a alteridade é o ponto crucial ao entendimento da existência de diferentes identidades. Na comunidade Surda, esse encontro é uma necessidade contínua. Nela, a alteridade vai se modelando, entre outros aspectos, desde a construção da identidade.

As afirmações identitárias, dos movimentos minoritários socioculturais, devem ser percebidas em um processo contínuo de relações de poder, entendendo que essas identidades mantêm um posicionamento contrário às culturas dominantes. Os novos movimentos sociais mostram que o problema não é obrigatoriamente quantitativo, mas uma junção de pensamentos hegemônicos. Segundo Barbalho (2005), "tais movimentos reúnem elementos da política-emancipatória, em sua luta por minimizar ou eliminar a exploração e a desigualdade, e da política-vida, na busca de afirmar a liberdade de escolha de um estilo de vida". (BARBALHO, 2005, p. 30).

Aqui é colocada uma nova dimensão para o conceito de cidadania, sugerido pelos movimentos sociais. Essa cidadania diz respeito à composição entre cultura e política, como laços característicos de um plano, que atua na disputa de hegemonia entre as construções culturais ocultas às imposições sociais, e uma cultura de formação democrática e processual.

\section{O direito ao reconhecimento}

Passamos a analisar se o Decreto de Lei número 5.626, de 22 de dezembro de 2005, que regulamenta a lei sobre a Língua Brasileira de Sinais (Lei Federal nº10436, de 24 de abril de 2002) e a Lei de Acessibilidade (nº 10.098, de 19 de dezembro de 2000), que estabelece normas básicas à promoção de acessibilidade, estão sendo obedecidos. A questão inserida no panorama atual é se a inclusão dos surdos no âmbito comunicacional e nos espaços urbanos ocorre de forma efetiva. É necessário que novas decisões sejam providenciadas e ações realizadas, para que fomentem a vivência entre surdos e ouvintes. Locais que deveriam promover esse tipo de iniciativa, como as universidades, têm ações bastante restritas.

Alguns dados, referentes até o ano de 2016, concedidos pela Secretaria de Acessibilidade da Universidade Federal do Ceará (UFCinclui), facilitam o entendimento: 
havia apenas dois alunos surdos na UFC - um da Faculdade de Economia, Administração, Atuária e Contabilidade (FEAAC) e um do curso de Letras. Após a criação do curso de Letras-Libras, em 2012, essa quantidade saltou para 39 (37 surdos matriculados em Letras-Libras somados aos dois veteranos). O uso da linguagem de Libras e habilitação do Surdo foi centro de muitos estudos5, principalmente após a constatação por Stokoe de que as línguas de sinais possuem uma estruturação semelhante às línguas orais e que satisfazem as mesmas funções, com possibilidades de expressão, seja qual for o nível de abstração.

No Brasil, o movimento multicultural, nos anos de 1980, induziu a luta dos Surdos por respeito e reconhecimento de sua língua, assim como a sua cultura (MOURA, 2000). Como efeito, ocorreu o fortalecimento da comunidade Surda, através de suas associações e federação - a Feneis - que solicitou o uso da Libras na educação de surdos, como segmento de uma ideologia que percebe o surdo não como deficiente, mas diferente e pertencente a um grupo linguístico minoritário (MOURA; HARRISON, 2010).

O movimento conseguiu o respaldo da comunidade científica, que tornou notória a necessidade de atender as reivindicações. A soma dessas ações, resultou nas leis $\mathrm{n}^{\mathrm{o}}$ 10.436, sobre a Língua Brasileira de Sinais, e no artigo 18 da Lei ${ }^{\circ} 10.098$, que, quando aprovados, foram regulamentados pelo decreto 5.626/05. Essa regulamentação passou a exigir que novas práticas de atuação fossem implementadas para que a ação exigida por lei ganhe condições de ser cumprida. "Sabe-se que apenas uma mudança total dos paradigmas possibilitará que uma modificação real tome corpo e possa tornar a lei efetiva" (MOURA; HARRISON, 2010, p. 335). A sociedade deve se adequar a essa realidade, pois as leis citadas já estabelecem normas a serem seguidas. O decreto 5.626/05, por exemplo, no capítulo I - das disposições preliminares - coloca que:

5 Com o tempo, os próprios surdos passaram a investigar a respeito das línguas de sinais. Porém, ainda são poucos os linguistas surdos pesquisando a língua de sinais do seu país. Ted Supalla e Carol Padden foram os primeiros linguistas surdos a estudarem a Língua de Sinais Americana, na década de 1980. Ana Regina e Souza Campello foi uma das primeiras surdas a estudar a língua de sinais do Brasil, em 2005. Ver REZENDE, Patrícia Luiza Ferreira; QUADROS, Ronice Muller de; PIZZIO, Aline Lemos. Estudos linguísticos das línguas de sinais. Coleção Letras Libras - Eixo formação específica. Universidade Federal de Santa Catarina, 2008. Disponível em: $<$ http://www.libras.ufsc.br/colecaoLetrasLibras/eixoFormacaoEspecifica/linguaBrasileiraDeSinaisI/scos/c ap18887/1.html>. Acesso: 01 nov. 2016. 
Art. 1o Este Decreto regulamenta a Lei no 10.436, de 24 de abril de 2002, e o art. 18 da Lei no 10.098, de 19 de dezembro de 2000. Art. 2o Para os fins deste Decreto, considera-se pessoa surda aquela que, por ter perda auditiva, compreende e interage com o mundo por meio de experiências visuais, manifestando sua cultura principalmente pelo uso da Língua Brasileira de Sinais - Libras (BRASIL, decreto $\mathrm{n}^{\circ} 5.626$, de 22 de dezembro de 2005).

Assim, prossegue no capítulo IV - do uso e da difusão da Libras e da língua portuguesa para o acesso das pessoas surdas à educação:

Art. 14. As instituições federais de ensino devem garantir, obrigatoriamente, às pessoas surdas acesso à comunicação, à informação e à educação nos processos seletivos, nas atividades e nos conteúdos curriculares desenvolvidos em todos os níveis, etapas e modalidades de educação, desde a educação infantil até a superior. Art. 15. Para complementar o currículo da base nacional comum, o ensino de Libras e o ensino da modalidade escrita da Língua Portuguesa, como segunda língua para alunos surdos, devem ser ministrados em uma perspectiva dialógica, funcional e instrumental, como: I - atividades ou complementação curricular específica na educação infantil e anos iniciais do ensino fundamental; e II - áreas de conhecimento, como disciplinas curriculares, nos anos finais do ensino fundamental, no ensino médio e na educação superior. (BRASIL, Decreto n 5.626, de 22 de dezembro de 2005).

A inserção da Língua Brasileira de Sinais no currículo de escolas e universidades bilíngues carrega mais do que o puro ensino de uma língua, porque faz com que os envolvidos nessa aprendizagem sintam a necessidade de conhecer a cultura surda e a forma de estar na sociedade, para atingir a compreensão e particularidades do surdo, além da relação com sua língua. A partir desses aspectos, é possível contemplar a singularidade dos sujeitos Surdos. Constatamos a importância desse reconhecimento, centro desta pesquisa, como está descrito na Lei n ${ }^{\circ}$ 436/02:

Art. 1o É reconhecida como meio legal de comunicação e expressão a Língua Brasileira de Sinais - Libras e outros recursos de expressão a ela associados. Entende-se como Língua Brasileira de Sinais - Libras a forma de comunicação e expressão, em que o sistema linguístico de natureza visual-motora, com estrutura gramatical própria, constitui um sistema linguístico de transmissão de ideias e fatos, oriundos de comunidades de pessoas surdas do Brasil. Art. 2o Deve ser garantido, por parte do poder público em geral e empresas concessionárias de serviços públicos, formas institucionalizadas de apoiar o uso e difusão da Língua Brasileira de Sinais - Libras como meio de comunicação objetiva e de utilização corrente das comunidades surdas do Brasil. Art. 3o As instituições públicas e empresas concessionárias de serviços públicos de assistência à saúde devem garantir atendimento e tratamento adequado aos portadores de deficiência auditiva, de acordo com as normas legais em vigor. Art. 4o O sistema educacional federal e os sistemas educacionais estaduais, municipais e do Distrito Federal devem garantir a inclusão nos cursos de formação de Educação Especial, de Fonoaudiologia e 
de Magistério, em seus níveis médio e superior, do ensino da Língua Brasileira de Sinais - Libras, como parte integrante dos Parâmetros Curriculares Nacionais - PCNs, conforme legislação vigente. Parágrafo único. A Língua Brasileira de Sinais - Libras não poderá substituir a modalidade escrita da língua portuguesa (BRASIL, Lei $n^{\circ} 436$, de 24 de abril de 2002).

\section{Considerações finais}

É esse respaldo que colabora para que a cultura surda, contida em um mundo sensitivo, seja vivenciada por quaisquer cidadãos interessados em conhecer pessoas diferentes de si mesmo. É preciso absorver e viver essas interações para que aconteça de fato a inclusão. O artigo I, da Lei 10.098/00 considera impedimento da plena vivência dos surdos a existência de barreiras, sejam de ordem atitudinal ou arquitetônicas, que atrapalhem ou impeçam "a participação social da pessoa, bem como o gozo, a fruição e o exercício de seus direitos à acessibilidade, à liberdade de movimento e de expressão, à comunicação, ao acesso à informação, à compreensão, à circulação com segurança, entre outros" (BRASIL, Lei n ${ }^{\circ} 10.098$, de 19 de dezembro de 2000). Esta lei coloca ainda que, para haver a comunicação entre quaisquer pessoas, deve ser levada em consideração:

A forma de interação dos cidadãos que abrange, entre outras opções, as línguas,
inclusive a Língua Brasileira de Sinais (Libras), a visualização de textos, o
Braille, o sistema de sinalização ou de comunicação tátil, os caracteres
ampliados, os dispositivos multimídia, assim como a linguagem simples,
escrita e oral, os sistemas auditivos e os meios de voz digitalizados e os modos,
meios e formatos aumentativos e alternativos de comunicação, incluindo as
tecnologias da informação e das comunicações (BRASIL, Lei n ${ }^{\circ} 10.098$, de 19
de dezembro de 2000).

As prerrogativas estão sendo adquiridas aos poucos. Enquanto isso, permanece a distância entre mundos diferentes, que evitam entrar em contato. De fato, é um assunto complexo, que precisa ser construído a partir dos ambientes escolares, contando com o apoio de intérpretes, que funcionam como base de apoio, no qual ouvinte e surdo possam compartilhar suas dúvidas, dificuldades e buscar soluções que contemplem as necessidades dos surdos de igual para igual com o ouvintismo. Aqui se revela a importância de promover ações de integração.

O artigo 24 do capítulo $X$, ainda da Lei $\mathrm{n}^{\circ}$ 10.098/00, nas disposições gerais, afirma que "o Poder Público promoverá campanhas informativas e educativas dirigidas à população em geral, com a finalidade de conscientizá-la e sensibilizá-la quanto à 


\section{míDiA

acessibilidade e à integração social da pessoa portadora de deficiência ou com mobilidade reduzida" (BRASIL, Lei $n^{\circ}$ 10.098, de 19 de dezembro de 2000). É vital tornar evidente para todos os membros de uma sociedade que os elementos implicados no processo de inclusão de surdos lidam com a linguagem em suas diversas formas de expressão, sejam elas através da comunicação gestual ou a expressão escrita. Saber agir e aceitar o outro, reconhecendo-se também como outro, é substancial para que uma proposta de inclusão ganhe forma e seja realizada. Devemos pensar em maneiras de integrar pessoas para chegarmos ao mínimo de vivência esperada, mesmo que não seja a ideal.

A comunidade Surda é bem plural e a maioria das pessoas parece não ver a sua existência. Neste trabalho, o leitor teve e tem acesso ao contexto histórico da educação dos surdos, marcada por retrocessos, até o reconhecimento da língua de sinais e sua inclusão; conhecer as leis que temos hoje sobre inclusão social e os direitos dos surdos; e compreender a Língua Brasileira de Sinais e sua importância no processo de socialização dos surdos. O movimento Surdo comporta uma luta que se perpetua até os dias atuais.

Verificamos ainda que a inclusão do surdo não está acontecendo como de fato deveria. Observamos também que os surdos, assim como as pessoas com quaisquer outras diferenças, sofrem preconceito e são estigmatizados. É importante que a sociedade busque conhecer seus direitos e ocorra uma mudança nas práticas pedagógicas, para que seja disseminada a filosofia bilíngue, oportunizando, desta forma, uma aprendizagem adequada para surdos, que são excluídos da maioria das instituições de ensino, seja por falta de metodologias, recursos ou até mesmo por boa vontade. As universidades e escolas podem promover essa troca de experiências e vivências de práticas comunicativas entre surdos e ouvintes, com métodos interativos e estimulantes, respeitando a dignidade de todos os indivíduos e se constituindo, assim, em uma iniciativa fundamental para o exercício da autonomia e da cidadania, na perspectiva de ampliação do processo de inclusão social dos surdos em toda a sociedade. 
Referências

BAKER-SHENK, Charlotte; COKELY, Dennis. American Sign Language: A teacher's resource text on curriculum, methods, and evaluation. Washington: Gallaudet University Press, 1980.

BARBALHO, Alexandre. Cultura minorias e mídia: ou algumas questões postas ao liberalismo. In: BARBALHO, Alexandre; PAIVA, Raquel (orgs.). Comunicação e cultura das minorias. São Paulo: Paulus, 2005.

BAUMAN, Zygmunt. Comunidade: a busca por segurança no mundo atual. Rio de Janeiro: Jorge Zahar, 2003.

BHABHA, Homi K. A questão do "outro": diferença, discriminação e o discurso do colonialismo. In: HOLANDA, Heloisa Buarque de (org.). Pós-modernismo e cultura. Rio de Janeiro: Rocco, 1992.

BRASIL. Decreto $\mathbf{n}^{\mathbf{0}}$ 5.626, de 22 de dezembro de 2005 .

BRASIL. Lei n⿳0 436, de 24 de abril de 2002.

BRASIL. Lei n $\mathbf{1 0 . 0 9 8}$, de 19 de dezembro de 2000.

CARVALHO, José Murilo de. Cidadania no Brasil: o longo caminho. Rio de Janeiro:

Civilização Brasileira, 2002.

DALCIN, Gladis. Um estranho no ninho: um estudo psicanalítico sobre a constituição da subjetividade do sujeito surdo. Dissertação de Mestrado. Universidade Federal de Santa Catarina. Florianópolis, 2005.

FOUCAULT, Michel. Microfísica do poder. Rio de Janeiro: Graal, 1990.

GOFFMAN, Erving. Estigma: Notas sobre a Manipulação da Identidade Deteriorada. São Paulo: LTC, 2004.

HALL, Stuart. Cultural studies and its theoretical legacies. In: MORLEY, David; KUANHSING, Chen. Stuart Hall: Critical dialogues in cultural studies. London; New York: Routledge, 2005.

Identidades culturais na pós-modernidade. Rio de Janeiro: DP\&A, 1997.

MOURA, Maria Cecília de. O surdo: caminhos para uma nova identidade. Rio de Janeiro: Revinter, 2000.

; HARRISON, Kathryn Marie Pacheco. A inclusão do surdo na universidade: mito ou realidade? Cadernos de Tradução, v. 2, n. 26, p. 333-358. Florianópolis: 2010.

PAIVA, Raquel. O espírito comum: comunidade, mídia e globalismo. Rio de Janeiro: Mauad, 2003.

PERLIN, Gládis Teresinha Tachetto. Identidades surdas. In: SKILIAR, Carlos (org.). A surdez: um olhar sobre as diferenças. Porto Alegre: Mediação, 1998.

O ser e o estar sendo surdos: alteridade, diferença e identidade. Tese de Doutorado. Faculdade de Educação. Universidade Federal do Rio Grande do Sul, Porto Alegre, 2003. 
QUADROS, Ronice Müller de; PERLIN, Gladis. O ouvinte: o outro lado do surdo. Anais do II Seminário Internacional Educação Intercultural, Gênero e Movimentos Sociais. Florianópolis: Fapeu-002, 2003.

RABINOW, Paul; HUBERT, Dreyfus. Michel Foucault: uma trajetória filosófica para além do estruturalismo e da hermenêutica. Rio de Janeiro: Forense Universitária, 1995.

REZENDE, Patrícia Luiza Ferreira; QUADROS, Ronice Muller de; PIZZIO, Aline Lemos. Estudos linguísticos das línguas de sinais. Coleção Letras Libras - Eixo formação específica. Universidade Federal de Santa Catarina, 2008. Disponível em: $<$ http://www.libras.ufsc.br/colecaoLetrasLibras/eixoFormacaoEspecifica/linguaBrasileiraDeSin aisI/scos/cap18887/1.html>. Acesso: 01 nov. 2016.

SÁ, Nídia Limeira de. Cultura, poder e educação de surdos. São Paulo: Paulinas, 2006.

SACKS, Oliver. Vendo vozes: uma jornada pelo mundo dos surdos. São Paulo: Companhia das Letras, 2010.

SKLIAR, Carlos (org.). A surdez: um olhar sobre as diferenças. Porto Alegre: Mediação, 1998.

A educação e a pergunta pelos Outros: diferença, alteridade, diversidade e os outros "outros". Ponto de Vista, n.05, p. 37-49. Florianópolis: 2003.

SODRÉ, Muniz. Por um conceito de minoria. In: PAIVA, Raquel; BARBALHO, Alexandre (orgs.). Comunicação e cultura das minorias. São Paulo: Paulus, 2005.

STROBEL, Karin Lilian. Surdos: vestígios culturais não registrados na história. Tese de Doutorado em Educação. Universidade Federal de Santa Catarina, Florianópolis, 2008.

VEIGA-NETO, Alfredo. Michel Foucault e educação: há algo de novo sob o sol? In: (org.). Crítica pós-estruturalista e educação. Porto Alegre: Sulina, 1995.

VIEIRA, Liszt. Os argonautas da cidadania: A sociedade civil na globalização. Rio de Janeiro: Record, 2001.

WILCOX, Phyllis Perrin; WILCOX, Sherman. Aprender a ver. Rio de Janeiro: Arara Azul, 2005.

WRIGLEY, Owen. Política da surdez. Florianópolis: UFSC, 2006. 